\title{
A Smart Growth Plan Based on the Improved Gini Coefficient
}

\author{
Zhang Yuwei, Yang Mengyue \\ School of Information, Beijing Wuzi University, Beijing 101149, China \\ Email: morbenvy@126.com
}

\begin{abstract}
Summary: The central idea of smart growth is that structured and strategic planning supports economic growth, addresses community needs, and protects the environment. The main assertion of this paper is to help implementing smart growth initiatives into cities' design. Considering the three E's of sustainability (they are Economically prosperous, socially Equitable, and Environmentally Sustainable) and the ten principles for smart growth, the paper selects a city as examples and obtains data from 2007 to 2014 from the comprehensive survey of cities managed by National Bureau of Statistics and uses SPSS to address the data and classify them into 12 index types considering the three E's of sustainability and the 10 principles of smart growth. We use two indexes to plot a curve and work out its area as the area coefficient similar to the Gini coefficient by Parabolic interpolation method. We improve the rationality of some values of area coefficient artificially and construct a reasonable judgment matrix. Next we assign the weight of each index in light of judgment matrix by MATLAB and design a function to measure the success of smart growth of city, which contains scores based on National Civilized City Evaluation System and weight values put on indexes according to the degree of building a smart growth city. The paper applies the method to choose the key factors relatively: greenbelt and garden area, amounts of fixed facilities and housing opportunities and choices. We give several suggestions to support the level of smart growth. The merits and demerits of the metric and extensions are also discussed in the last part.
\end{abstract}

Keywords: Smart growth; gini coefficient; parabolic interpolation method.

\section{Introduction}

Smart growth is an urban planning and transportation theory that concentrates growth in compact walkable urban centers to avoid sprawl. It also advocates compact, transit-oriented, walkable, bicycle-friendly land use, including neighborhood schools, complete streets, and mixed-use development with a range of housing options [1]. Smart growth is an urban planning theory that originated in the USA in 1990's but the ideas behind the concept have long existed, including the 1990 "Green Paper on the Urban Environment", and the 2001 "Strategy for Sustainable Development". These strategic documents advocate for urban growth that is managed efficiently to avoid economic inefficiency, ecological catastrophe, and social inequity[2]. The term 'smart growth' is particularly used in North America. In Europe and particularly the UK, the terms 'Compact City' or 'urban intensification' have often been used to describe similar concepts that have influenced government planning policies in the UK, the Netherlands and several other European countries[3]. Smart growth values long-range, regional considerations of sustainability over a short-term focus. Its sustainable development goals are to achieve a unique sense of community and place; expand the range of transportation, employment, and housing choices; equitably distribute the costs and benefits of development; preserve and enhance natural and cultural resources; and promote public health[4][5].

There are many researches on Smart growth throughout the world recently, including the paper building an evaluation system to measure the smart growth of a city and developing a growth plan[6]. In terms of three E's of sustainability and the ten principles for smart growth, the paper uses structural equation modeling to identify a second-order latent construct of the built environment indicated by land use mix, employment concentration, and pedestrian-oriented design features which are based on Smart Growth[7]. And the paper suggests that there is the need to balance smart compact cities and smart green cities these two aspects to develop a systemic approach towards smart-compact-green cities[8]. And the paper aims to determine the effect of smart growth on the operational energy of drinking water distribution[9]. The research examined whether smart growth policies reduce the urban heat island (UHI) effect by deriving 
five alternative neighborhood planning scenarios for Brisbane for 2023: business as usual, transit oriented development (TOD), infill development, motorway corridor oriented development, and sprawl development[10]. And the chapter traces the history of urban development in the USA after the Second World War, rather than slowing or stopping urban growth, planners can use this New Urbanism for Smart Growth - a potential win-win for residents, the building industry, communities, and the environment[11].

Jinchang is a mid-sized city in China. It's an industrial city in Gansu province the northwest of China with a population of 460,000. Jinchang is an oasis in the desert without exaggeration. It has 2575 square kilometers of the oasis and 2535 square kilometers of the desert around it. Jinchang is one of the National civilized cities in China (National civilized city is the highest and the most comprehensive honor given by the relevant authority of China, reflecting the overall level of civilization of the city) and some indexes of three E's of sustainability or the ten principles of smart growth theory can be easily chosen from the assessment standard to measure the success of smart growth of the city. Smart city theory is usually used to measure the degree of urban development, and its concept is similar to that of China's civilized cities. Persistently high natural population growth is the most significant cause of urban population growth in Jinchang, though the degree of its importance varies among countries. Jinchang, one of the largest cities in Gansu province, grew at an average of 5.6\% rate per annum between 1982 and 201.0, even though it was built in 1981. Over the next 20 to 30 years, the population in general and the urban population in particular are expected to increase at an even higher rate[12]. So Jinchang is introduced as an example for analysis.

\section{Method}

\subsection{Gini Coefficient}

Methods Lorenz curve and Gini coefficient in economics, the Lorenz curve is often used to explain and measure the heterogeneity of the wealth distribution. It is a graphical representation of the cumulative distribution function of the empirical probability distribution. The Gini coefficient is usually defined mathematically based on the Lorenz curve, which plots the proportion of the total income of the population ( $\mathrm{y}$ axis) that is cumulatively earned by the bottom $\mathrm{x} \%$ of the population. The line at 45 degrees thus represents perfect equality of incomes. The Gini coefficient can then be thought of as the ratio of the area that lies between the line of equality and the Lorenz curve (marked A in the diagram) over the total area under the line of equality (marked A and B in the diagram). The graph shows that the Gini coefficient is equal to the area marked A divided by the sum of the areas marked $\mathrm{A}$ and $\mathrm{B}$, that is, Gini $=\mathrm{A} /(\mathrm{A}+\mathrm{B})$. It is also equal to $2 \mathrm{~A}$ and to $1-2 \mathrm{~B}$ due to the fact that $\mathrm{A}+\mathrm{B}=0.5$ (since the axes scale from 0 to 1). For example, the Graphical representation of the Gini coefficient is shown in Figure 1.

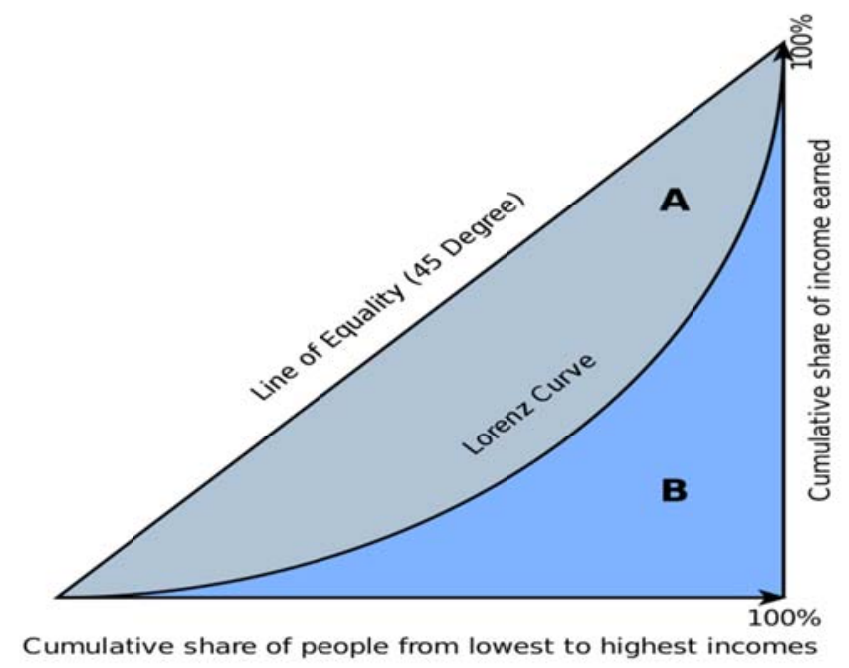

Figure 1. Graphical representation of the Gini coefficient 


\subsection{Advanced Method}

Gini coefficient is introduced to assess the relationships between the indexes that have been recommended.

Gini coefficient is a measure of statistical dispersion intended to represent the income or wealth distribution of a nation's residents, and it is the most commonly used measure of inequality. Therefore, it is applied to measure the degree of interaction among all indicators. The principles are as follows:

1. Use indexes to replace the original horizontal ordinate and vertical coordinates

2. A generalization of Parabolic interpolation method was applied to work out the area that lies between the line of equality and the Lorenz curve and they were applied to represent the degree.

3. Artificially improve the rationality of some numbers to construct a reasonable judgment matrix.

Use two indexes to plot a curve and work out its area as the area coefficient similar to the Gini coefficient. The Graphical representation of the Gini coefficient is shown in Figure 1.

\section{$3 \quad$ Problem Analysis}

\subsection{Theory}

Some indexes of three E's of sustainability are chosen from the assessment standard. Then the advanced method has been put forward to put the different weight on these indexes and created a function related to them to measure the success of smart growth of the city. This function F include variables $\mathrm{f}_{i}$ and $\omega_{i}$.

$$
\mathrm{F}=\sum_{i=1}^{n} \omega_{i} f_{i}
$$

F: the criterion as the measurement the success of smart growth

$\mathrm{f}_{i}$ : scores based on National Civilized City Evaluation System

$\omega_{i}$ : weigh values put on indexes according to the degree of outcome

The $\mathrm{F}$ is the metric to measure the success of smart growth of a city.

\subsection{Data Collection}

The data is obtained from 2007 to 2014 from the comprehensive survey of cities managed by National Bureau of Statistics. This period was selected mainly because the statistical caliber and classification system of the data were consistent and the data were complete. SPSS is used to address the data and classify them into 12 index types considering the three E's of sustainability and the 10 principles of smart growth. Because some principles are not quantifiable easily, they are discussed in the next part. The selection of factors is shown in Figure2 and the data of each indicator are shown in Table1-12 that come from National Bureau of Statistics. These indexes are as following,

1. amount of residential areas

2. urban population ratio

3. amount of tertiary industry

4. average wage

5. amount of fixed facilities

6 . health status

7. traffic status

8. education level

9. greenbelts and gardens areas

10. price index number

11. per-capita energy consumption

12. gross product 


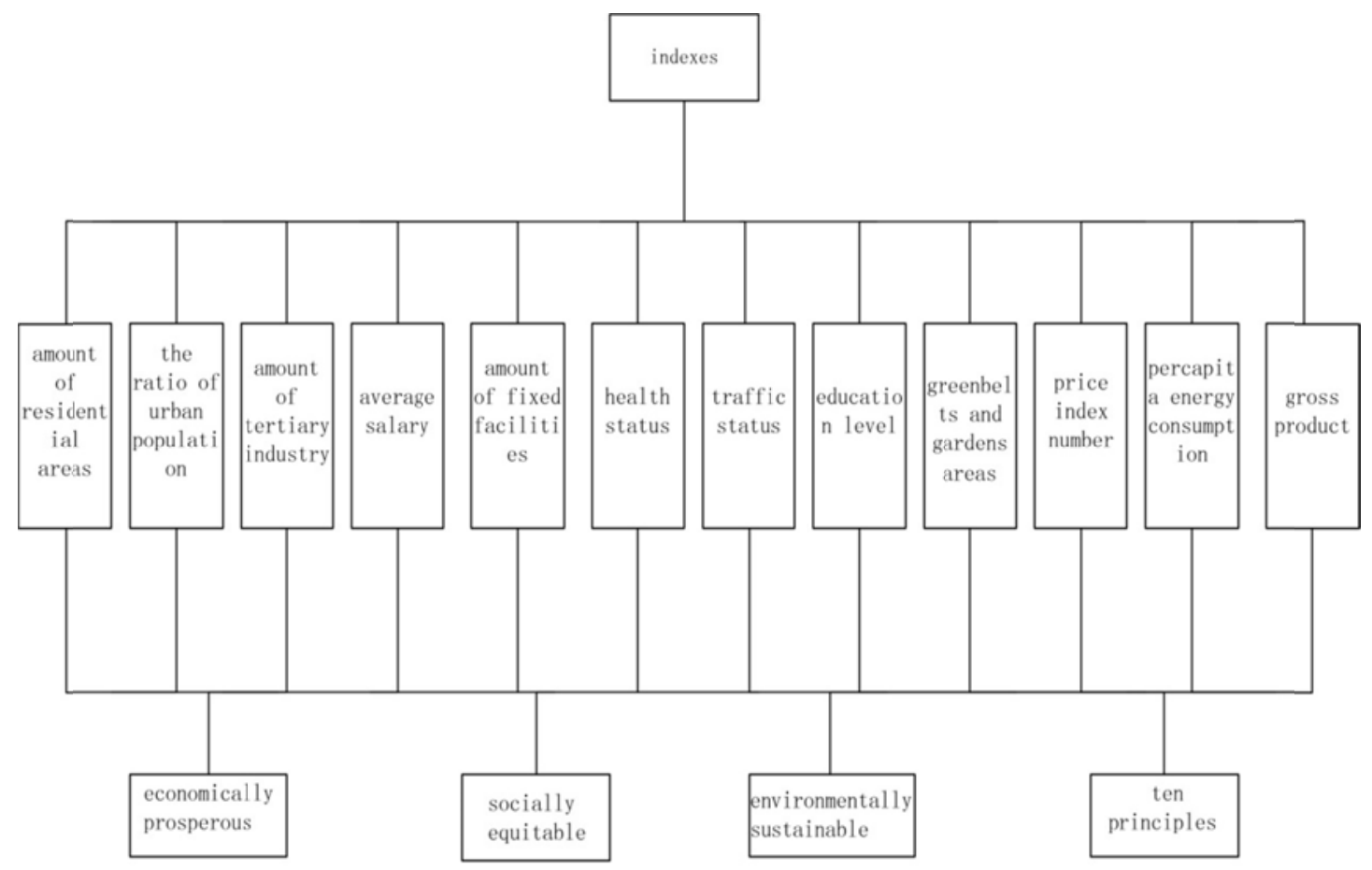

Figure 2. Selection of factors

Table 1. Amount of residential areas

\begin{tabular}{c|c|c|c|c|c|c|c|c}
\hline year & 2007 & 2008 & 2009 & 2010 & 2011 & 2012 & 2013 & 2014 \\
\hline amount & 211.2 & 223 & 209.1 & 217 & 208.2 & 196.6 & 206.3 & 202.9 \\
\hline percentage & 12.61 & 13.32 & 12.49 & 12.96 & 12.44 & 11.74 & 12.32 & 12.12 \\
\hline cumulative percent & 12.61 & 25.93 & 38.42 & 51.38 & 63.82 & 75.56 & 87.88 & 100 \\
\hline
\end{tabular}

Table 2. Urban population ratio

\begin{tabular}{c|c|c|c|c|c|c|c|c}
\hline year & 2007 & 2008 & 2009 & 2010 & 2011 & 2012 & 2013 & 2014 \\
\hline Urban population ratio & 59.64 & 59.73 & 60.32 & 62.17 & 63.1 & 64.13 & 65.518 & 66.92 \\
\hline Percentage & 11.89 & 11.91 & 12.03 & 12.39 & 12.58 & 12.79 & 13.017 & 13.34 \\
\hline Cumulative percent & 11.89 & 23.8 & 35.82 & 48.22 & 60.8 & 73.58 & 86.616 & 100 \\
\hline
\end{tabular}

Table 3. Amount of tertiary industry (Unit: 100 million yuan)

\begin{tabular}{c|c|c|c|c|c|c|c|c}
\hline Year & 2007 & 2008 & 2009 & 2010 & 2011 & 2012 & 2013 & 2014 \\
\hline amount of tertiary industry & 1037.11 & 1234.21 & 1395.43 & 1599.2 & 2018.99 & 234.5 .93 & 2740.65 & 3009.61 \\
\hline Percentage & 6.74 & 8.02 & 9.07 & 10.4 & 13.13 & 15.25 & 17.82 & 19.57 \\
\hline Cumulative percent & 6.74 & 14.77 & 23.84 & 34.24 & 47.36 & 62.61 & 80.43 & 100 \\
\hline
\end{tabular}

Table 4. Average wage (Unit: yuan)

\begin{tabular}{c|c|c|c|c|c|c|c|c}
\hline Year & 2007 & 2008 & 2009 & 2010 & 2011 & 2012 & 2013 & 2014 \\
\hline Average Wage & 20657 & 23524 & 26743 & 29096 & 32092 & 37679 & 42833 & 46960 \\
\hline Percentage & 7.96 & 9.06 & 10.3 & 11.21 & 12.36 & 14.52 & 16.5 & 18.09 \\
\hline Cumulative percent & 7.96 & 17.02 & 27.32 & 38.53 & 50.89 & 65.41 & 81.91 & 100 \\
\hline
\end{tabular}


Table 5. Amount of fixed facilities

\begin{tabular}{c|c|c|c|c|c|c|c|c}
\hline Year & 2007 & 2008 & 2009 & 2010 & 2011 & 2012 & 2013 & 2014 \\
\hline Amount of fixed facilities & 49.93 & 50.06 & 50.94 & 54.26 & 56.53 & 59.53 & 65.04 & 67.02 \\
\hline Percentage & 11.01 & 11.04 & 11.24 & 11.97 & 12.47 & 13.13 & 14.36 & 14.78 \\
\hline Cumulative percent & 11.01 & 22.05 & 33.29 & 45.26 & 57.73 & 70.86 & 85.22 & 100 \\
\hline
\end{tabular}

Table 6. Health status

\begin{tabular}{c|c|c|c|c|c|c|c|c}
\hline Year & 2007 & 2008 & 2009 & 2010 & 2011 & 2012 & 2013 & 2014 \\
\hline Total & 11940 & 10737 & 10011 & 10267 & 10065 & 9551 & 9855 & 11216 \\
\hline Percentage & 14.28 & 12.84 & 11.97 & 12.27 & 12.03 & 11.42 & 11.78 & 13.41 \\
\hline Cumulative percent & 14.28 & 27.11 & 39.08 & 51.36 & 63.39 & 74.81 & 86.59 & 100 \\
\hline
\end{tabular}

Table 7. Traffic status (Unit:km)

\begin{tabular}{c|c|c|c|c|c|c|c|c}
\hline Year & 2007 & 2008 & 2009 & 2010 & 2011 & 2012 & 2013 & 2014 \\
\hline Length of Highways & 1586.74 & 1702.45 & 1976.14 & 2035.66 & 2188.59 & 2518.45 & 2668.51 & 2808.52 \\
\hline Percentage & 9.07 & 9.74 & 11.3 & 11.64 & 12.52 & 14.4 & 15.26 & 16.06 \\
\hline Cumulative percent & 9.07 & 18.81 & 30.11 & 41.75 & 54.27 & 68.67 & 83.94 & 100.00 \\
\hline
\end{tabular}

Table 8. Education level (The number of college students per 10,000 population)

\begin{tabular}{c|c|c|c|c|c|c|c|c}
\hline Year & 2007 & 2008 & 2009 & 2010 & 2011 & 2012 & 2013 & 2014 \\
\hline Amount of graduates & 113 & 126 & 137 & 149 & 158 & 168 & 172 & 175 \\
\hline Percentage & 9.44 & 10.52 & 11.43 & 12.44 & 13.19 & 14.02 & 14.32 & 14.64 \\
\hline Cumulative percent & 9.44 & 19.96 & 31.39 & 43.83 & 57.02 & 71.04 & 85.36 & 100 \\
\hline
\end{tabular}

Table 9. Greenbelts and gardens areas (Unit: hectare)

\begin{tabular}{c|c|c|c|c|c|c|c|c}
\hline Year & 2007 & 2008 & 2009 & 2010 & 2011 & 2012 & 2013 & 2014 \\
\hline Urban garden green area & 987 & 1000 & 1058 & 1091 & 1113 & 1130 & 1258 & 1302.9 \\
\hline Percentage & 11.04 & 11.19 & 11.83 & 12.2 & 12.45 & 12.64 & 14.07 & 14.58 \\
\hline Cumulative percent & 11.04 & 22.23 & 34.06 & 46.26 & 58.71 & 71.35 & 85.42 & 100 \\
\hline
\end{tabular}

Table10. Price index number

\begin{tabular}{c|c|c|c|c|c|c|c|c}
\hline Year & 2007 & 2008 & 2009 & 2010 & 2011 & 2012 & 2013 & 2014 \\
\hline price index number & 98.7 & 99.9 & 100.5 & 104.8 & 105.6 & 101.6 & 101.9 & 101.6 \\
\hline percentage & 12.12 & 12.26 & 12.34 & 12.86 & 12.96 & 12.47 & 12.51 & 12.47 \\
\hline Cumulative percent & 12.12 & 24.38 & 36.72 & 49.58 & 62.54 & 75.02 & 87.53 & 100 \\
\hline
\end{tabular}

Table11. Annual Per Capita Consumption for Households (kg of SCE)

\begin{tabular}{l|l|l|l|l|l|l|l|l}
\hline Year & 2007 & 2008 & 2009 & 2010 & 2011 & 2012 & 2013 & 2014 \\
\hline Per capita energy & 147.24 & 164.4 & 186.55 & 216.53 & 251.11 & 266.19 & 283.94 & 298.9 \\
\hline percentage & 8.11 & 9.06 & 10.28 & 11.93 & 13.84 & 14.67 & 15.65 & 16.46 \\
\hline Cumulative percent & 8.11 & 17.17 & 27.45 & 39.38 & 53.22 & 67.89 & 83.54 & 100 \\
\hline
\end{tabular}


Table12. Gross product (Unit: 0.1billion)

\begin{tabular}{c|c|c|c|c|c|c|c|c}
\hline year & 2007 & 2008 & 2009 & 2010 & 2011 & 2012 & 2013 & 2014 \\
\hline gross product & 2703.98 & 3166.82 & 3478.07 & 4135.86 & 5002.41 & 5675.18 & 6330.69 & 6836.82 \\
\hline percentage & 7.24 & 8.48 & 9.32 & 11.08 & 13.4 & 15.2 & 16.96 & 18.31 \\
\hline Cumulative percent & 7.24 & 15.73 & 25.04 & 36.12 & 49.52 & 64.73 & 81.69 & 100 \\
\hline
\end{tabular}

\subsection{Data Analysis}

The advanced method is put the different weight on these indexes and created a function related to them to measure the success of smart growth of the city. The area that lies between the line of equality and the Lorenz curve represent the relationship between the two indexes. For example, $A_{i}-A_{j}$ represent the relationship between $A_{i}$ and $A_{j}, \mathrm{i} \neq \mathrm{j}$. Since the values of the areas range between 0 and 1 , when we obtained the values of areas that are negative, we improve the rationality of some numbers to construct a reasonable judgment matrix artificially combined with the physical truth.

$\mathrm{A}_{1}$ : amount of residential areas

$\mathrm{A}_{2}$ : urban population ratio

$\mathrm{A}_{3}$ : amount of tertiary industry

$\mathrm{A}_{4}$ : average wage

$\mathrm{A}_{5}$ : amount of fixed facilities

$\mathrm{A}_{6}$ : health status

$\mathrm{A}_{7}$ : traffic status

$\mathrm{A}_{8}$ : education level

$\mathrm{A}_{9}$ : greenbelts and gardens areas

$\mathrm{A}_{10}$ : price index number

$\mathrm{A}_{11}$ : per-capita energy consumption

$\mathrm{A}_{12}$ : gross product

$f_{1 \mathrm{i}}$ : the scores Jinchang obtained

$\mathrm{f}_{2 \mathrm{i}}$ : the scores Jinchang obtained after improvement

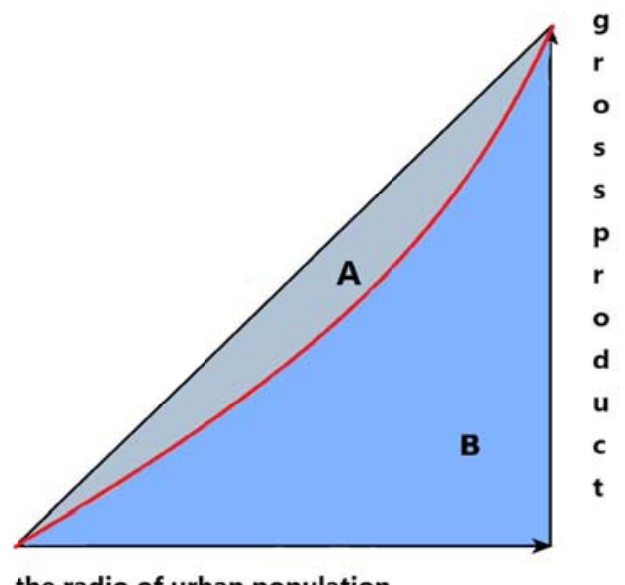

the radio of urban population

Figure 3. Graphical representation of the advanced

The advanced method is adopted to measure the degree of interaction. For example, $\mathrm{x}$ axis represent the ratio of urban population, $\mathrm{y}$ axis represent the gross product. The area of A accounts for one fifth of the area of right triangle. The value of $\mathrm{A} /(\mathrm{A}+\mathrm{B})$ means the degree of relationship between $\mathrm{x}$ and $\mathrm{y}$. The 
interaction of the two indicators is that only when the majority of gross product is created by the majority of people can produce greater gross product, and is also a fair to the urban people and can promote the positive development of the city.

As shown in Figure3, the data of Jinchang over the past two to three decades plot the Lorenz curve. The line of equality shows that the ratio of urban population and the gross product are matched in the past years, and the relationship between the urban population and the gross product is close.

Table13. Judgment matrix

\begin{tabular}{c|c|c|c|c|c|c|c|c|c|c|c|c}
\hline & $A_{1}$ & $A_{2}$ & $A_{3}$ & $A_{4}$ & $A_{5}$ & $A_{6}$ & $A_{7}$ & $A_{8}$ & $A_{9}$ & $A_{10}$ & $A_{11}$ & $A_{12}$ \\
\hline$A_{1}$ & 1 & 3 & $1 / 3$ & 7 & $1 / 5$ & $1 / 7$ & $1 / 5$ & 3 & $1 / 7$ & 5 & 3 & 5 \\
\hline$A_{2}$ & $1 / 3$ & 1 & $1 / 5$ & $1 / 3$ & $1 / 5$ & $1 / 5$ & $1 / 7$ & $1 / 3$ & $1 / 7$ & 3 & $1 / 3$ & 5 \\
\hline$A_{3}$ & 3 & 5 & 1 & 5 & $1 / 3$ & $1 / 7$ & $1 / 5$ & $1 / 5$ & $1 / 7$ & 5 & $1 / 3$ & $1 / 3$ \\
\hline$A_{4}$ & $1 / 7$ & 3 & $1 / 5$ & 1 & $1 / 5$ & $1 / 3$ & $1 / 5$ & $1 / 5$ & $1 / 7$ & 5 & $1 / 5$ & $1 / 5$ \\
\hline$A_{5}$ & 5 & 5 & 3 & 5 & 1 & 3 & $1 / 3$ & $1 / 7$ & $1 / 7$ & $1 / 3$ & $1 / 3$ & $1 / 5$ \\
\hline$A_{6}$ & 7 & 5 & 7 & 3 & $1 / 3$ & 1 & 7 & 7 & 3 & $1 / 5$ & 7 & 3 \\
\hline$A_{7}$ & 5 & 7 & 5 & 5 & 3 & $1 / 7$ & 1 & $1 / 7$ & $1 / 7$ & 5 & $1 / 5$ & 5 \\
\hline$A_{8}$ & $1 / 3$ & 3 & 5 & 5 & 7 & $1 / 7$ & 7 & 1 & $1 / 3$ & 5 & 1 & 3 \\
\hline$A_{9}$ & 7 & 7 & 7 & 7 & 7 & $1 / 3$ & 7 & 3 & 1 & 7 & 7 & 7 \\
\hline$A_{10}$ & $1 / 5$ & $1 / 3$ & $1 / 5$ & $1 / 5$ & 3 & 5 & $1 / 5$ & $1 / 5$ & $1 / 7$ & 1 & 5 & 3 \\
\hline$A_{11}$ & $1 / 3$ & 3 & 3 & 5 & 3 & $1 / 7$ & 5 & 1 & $1 / 7$ & $1 / 5$ & 1 & 7 \\
\hline$A_{12}$ & $1 / 5$ & $1 / 5$ & 3 & 5 & 5 & $1 / 3$ & $1 / 5$ & $1 / 3$ & $1 / 7$ & $1 / 3$ & $1 / 7$ & 1 \\
\hline
\end{tabular}

In order to test whether the judgment is consistent, the consistency of matrix is tested, which is shown in Table 13. Otherwise, a new judgment matrix is constructed and recheck the consistency until the consistency is passed. Then the eigenvalues and eigenvectors of the matrix are obtained and the normalized processing is carried out to get the weight value of each index.

Table14. Information of the city

\begin{tabular}{c|c|c|c}
\hline & $f_{1 i}$ & $f_{2 i}$ & $\omega_{i}$ \\
\hline$A_{1}$ & 74 & 76 & 0.072 \\
\hline$A_{2}$ & 70 & 71 & 0.029 \\
\hline$A_{3}$ & 86 & 88 & 0.05 \\
\hline$A_{4}$ & 75 & 77 & 0.031 \\
\hline$A_{5}$ & 80 & 85 & 0.069 \\
\hline$A_{6}$ & 80 & 80 & 0.174 \\
\hline$A_{7}$ & 74 & 76 & 0.072 \\
\hline$A_{8}$ & 70 & 71 & 0.029 \\
\hline$A_{9}$ & 86 & 88 & 0.05 \\
\hline$A_{10}$ & 75 & 77 & 0.031 \\
\hline$A_{11}$ & 80 & 85 & 0.069 \\
\hline$A_{12}$ & 80 & 80 & 0.174 \\
\hline
\end{tabular}


In the light of ranking of each factor, urban population ratio accounts for the least percentage of all indexes. So the motivation for building smart growth cities is insufficient.

According to the metric which have defined to measure the success of smart growth of a city, the value of $\mathrm{F}$ of Jinchang is $77.437 \%$, which is shown in Table 14. So current growth plans of Jinchang are in line with the smart growth theories and they are successful. The flow chart for assigning weights is shown in Figure 4.

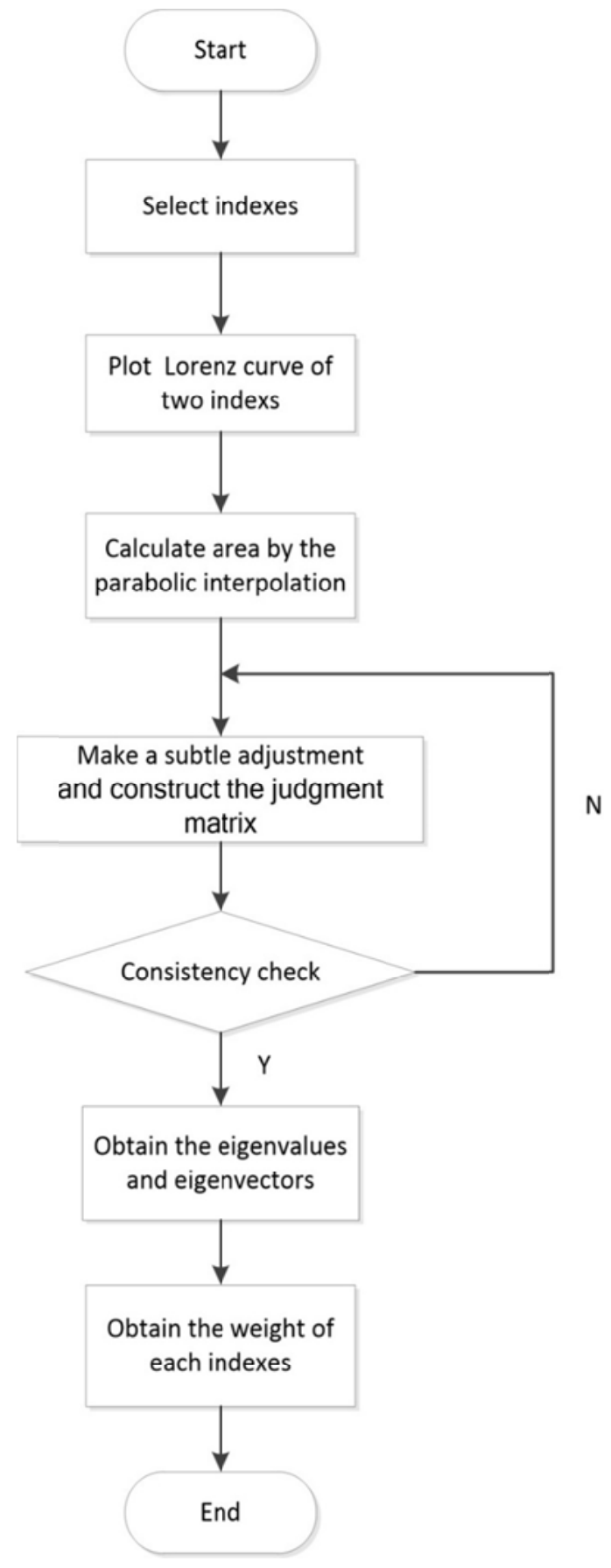

Figure 4. The flow chart for assigning weights 


\subsection{Other Indexes without Quantification}

The "where" of smart growth contains location and land use problems, while the "how" exclusively concerns the design of neighborhoods, buildings, and infrastructure. Considering these two notions, while adjusting the principles of smart growth to best meet the needs and constraints of their particular area and directing transportation plans and programs accordingly, allow policy makers to maintain a high quality of life in their community while meeting the demand for energy and reducing total energy consumption[4].

Policies that offer more traffic choices can immediately affect public health by reducing air pollution from driving while increasing physical activity. Compact and mixed-use communities with streets provide pedestrians and cyclists with the opportunity to incorporate physical activity into their daily lives by walking or cycling to school, work, transit, shops, restaurants or for recreation.

A key tenet of smart growth is promoting compact urban development, which is considered economically efficient and environmentally friendly. Areas inside the boundary are zoned for urban use, and those outside the boundary are usually zoned for rural uses. The key purpose of an urban growth boundary is to contain, control, direct, or phase growth in order to promote a more compact and contiguous urban development. Urban growth boundaries are also established to protect farmlands and other resource lands, such as watersheds or wildlife habitats, from scattershot or low density development. Urban growth boundaries are usually drawn to accommodate expected growth for a specific period of time though they are periodically reassessed and expanded as needed. [5]

These strategies have one overarching goal: Rather than concentrating development at the urban fringe, urban development efforts should encourage greater compactness and an efficient use of already developed urban areas.

\section{Conclusion}

Government in Jinchang should accord with smart growth principles to adopt and implement land-use policies and regulations that support compact and inclusive communities. For example, regional governments can enact policies and regulations that require all real estate developers to provide a wide range of housing types (including various dwelling types, tenure, or floor space) in all new and emerging communities.

Under this circumstance, the following predictions are made:

1. GDP growth of about $7 \%$, of which: the first industry growth of about $5 \%$, the second industry growth of about $6 \%$, the tertiary industry growth of about $9 \%$

2. Increase of industrial added value above designated size by $5.5 \%$

3. Fixed asset investment increased by about $9 \%$

4. General public budget revenue growth of about $6 \%$

5. Total retail sales of social consumer goods increased by about $8 \%$

6. Total import and export trade increased by $5 \%$

7. Per capita disposable income of urban and rural residents increased by $8 \%$ and around $10 \%$

8. The consumer price index rose less than $3 \%$

9. The urbanization rate of household registration and resident population increased by 1 and 2 percentage points

10. The registered urban unemployment rate is controlled within $4 \%$

11. Based on the above data analysis and the metric introduced, the following corrective measures are proposed to help the cities improve.

12. Unwavering Government Commitment to Urban Growth Management.

Most fundamental lesson that the two cities have chosen can be the value of an unwavering commitment by municipal governments to urban growth management. Growth management policies in general and smart growth principles in particular are being promoted as an integral component of official plans.

13. Provide a variety of transportation choices.

Policies that offer more traffic choices can immediately affect public health by reducing air pollution from driving while increasing physical activity. Compact and mixed-use communities with streets provide pedestrians and cyclists with the opportunity to 
incorporate physical activity into their daily lives by walking or cycling to school, work, transit, shops, restaurants or for recreation.

14. Compact Urban Development

A key tenet of smart growth is promoting compact urban development, which is considered economically efficient and environmentally friendly. Various public legislations and regulatory approaches have been adopted to contain urban growth, most notably through urban growth boundaries and greenbelts.

15. Avoid piecemeal planning schemes

Another significant element of the smart growth principles that could and should to be adopted is a comprehensive urban development strategy. Indeed, deliberate physical planning efforts are either lacking or are woefully outdated in Jinchang,. Those that are being made do not provide for connections between land-use planning and recent policies for economic growth.

16. Infill Development

The smart growth initiative promotes reinvestment in existing urban areas, most notably the redevelopment of brownfield sites. Brownfields are abandoned, idled, or under-utilized industrial and commercial facilities where expansion or redevelopment is complicated by real or perceived contamination.

\section{References}

1. Novakowski, N. (2010). Smart urban growth for china, edited by yan song and chengri ding. Journal of Regional Science, 50(5), 1010-1011.

2. Arku, G. (2009). Rapidly growing african cities need to adopt smart growth policies to solve urban development concerns. Urban Forum,20(3), 253-270.

3. Department of Communities and Local Government, Planning Policy Guidance 2: Green Belts (London: DCLG, 2001), para.1.4.

4. EPA, "This is Smart Growth." 2016. https://www.epa.gov/smartgrowth/smart-growth-publication

5. Buehring, A. A., Freedberg, M., Gray, R., Santangelo, R., \& Stromberg, A. E. . Smart growth: a guide to developing and implementing greenhouse gas reductions programs.

6. Yun-Long, M. A., Chen, X., \& Luo, S. (2017). Quantitative analysis of urban intelligence and ranking the potential of individual initiatives within a designed smart growth plan. Ecological Economy(1).

7. Gehrke, S. R., \& Clifton, K. J. (2017). A pathway linking smart growth neighborhoods to home-based pedestrian travel. Travel Behaviour \& Society, 7, 52-62.

8. Artmann, M., Kohler, M., Meinel, G., Jing, G., \& Ioja, I. C. (2017). How smart growth and green infrastructure can mutually support each other - a conceptual framework for compact and green cities. Ecological Indicators.

9. Santana, M. V., Zhang, Q., Nachabe, M. H., Xie, X., \& Mihelcic, J. R. (2017). Could smart growth lower the operational energy of water supply? a scenario analysis in tampa, florida, usa. Landscape \& Urban Planning, 164, 99-108.

10.Deilami, K., \& Kamruzzaman, M. (2017). Modelling the urban heat island effect of smart growth policy scenarios in brisbane. Land Use Policy, 64, 38-55.

11.Nielsen, E. S. (2017). Sprawl and Smart Growth. Smart Growth Entrepreneurs. Springer International Publishing. 12.Wikipedia (2017). Jinchang. https://en.wikipedia.org/wiki/Jinchang 